\title{
Analisis Lingkungan Pengendapan Dan Pola Persebaran Reservoir Batupasir Formasi Talangakar, Sub Cekungan Ciputat, Cekungan Jawa Barat Utara
}

\author{
Hasnan Luthfi Dalimunthe ${ }^{(1, a) *}$, M. Syaifudin ${ }^{(1)}$, C. Prasetyadi ${ }^{(1)}$ dan \\ Mill Sartika Indah ${ }^{(2)}$ \\ (I) Program Studi Magister Teknik Geologi, Universitas Pembangunan Nasional Veteran Yogyakarta \\ ${ }^{(2)}$ Development Geologist PT. Pertamina UTC, Jakarta \\ ${ }^{a)}$ E-mail: hasnanluthfi@gmail.com
}

Diterima (29 Maret 2021), Direvisi (Tanggal 23 Mei 2021)

\begin{abstract}
Abstrak The North West Java Basin has several Sub Basins that have hydrocarbon resources, one of which is the Ciputat Sub Basin which in 2007 succeeded in carrying out hydrocarbon drilling in the Talangakar Formation with a stratigraphic trap system. The identification of the depositional environment is very important to see the pattern of reservoir distribution and changes in conditions that occur with the help of seismik and well data integration. This study uses analysis of any available data such as well log data and seismik data supported by the results of biostratigraphic and petrographic analysis. The results of the data analysis obtained an interpretation of the depositional facies in each sequence in the Talangakar Formation in the "X" Field, Ciputat Sub Basin, North West Java Basin, and then produced an interpretation of the depositional environment. The final stage of the research is to make a depositional environment map at each sequence boundary showing the distribution of the sandstone reservoir with the help of the RMS seismik attribute. Based on the map, the conditions of deposition by a tidal system in seawater The RMS attribute map anomaly shows a potential lead located in the south of sequence 1 spreading from West-East.
\end{abstract}

Keywords : Ciputat sub basin, sequence stratigraphy, facies, seismic attribute, sandstone reservoir

\begin{abstract}
Abstrak Cekungan Jawa Barat Utara memiliki beberapa Sub Cekungan yang memiliki sumber daya hidrokarbon salah satunya adalah Sub Cekungan Ciputat yang dimana pada tahun 2007 berhasil melakukan pemboran hidrokarbon pada Formasi Talangakar dengan sistem cebakan stratigrafi. Identifikasi lingkungan pengendapan sangat penting untuk mengetahui pola persebaran reservoir dan perubahan fasies yang terjadi dengan bantuan integrasi data sumur dan seismik. Penelitian ini menggunakan analisis setiap data yang sudah tersedia seperti data log sumur dan data seismik yang didukung dengan hasil analisis biostratigrafi dan petrografi. Hasil dari analisis dari data-data tersebut kemudian diperoleh interpretasi dari fasies pengendapan pada setiap sikuen pada Formasi Talangakar di Lapangan "X", Sub Cekungan Ciputat, Cekungan Jawa Barat Utara, dan kemudian menghasilkan interpretasi lingkungan pengendapannya. Akhir dari tahap penelitian adalah dilakukan pembuatan peta lingkungan pengendapan pada setiap batas sikuen yang menunjukkan distribusi penyebaran dari reservoir batupasir dengan bantuan atribut seismik RMS. Berdasarkan peta fasies, kondisi pengendapan dipengaruhi oleh suatu sistem pasang surut air laut. Anomali peta atribut RMS menunjukkan adanya potensi leads yang berada pada selatan sikuen 1 terbentang dari Barat-Timur.
\end{abstract}

Kata kunci : Sub-cekungan Ciputat, sikuen stratigrafi, fasies, seismic atribut, reservoir batupasir 


\section{PENDAHULUAN}

Cekungan Jawa Barat Utara memiliki beberapa Sub Cekungan yang memiliki sumber daya hidrokarbon salah satunya adalah Sub Cekungan Ciputat yang dimana pada tahun 2007 berhasil melakukan pemboran hidrokarbon pada Formasi Talangakar dengan sistem cebakan stratigrafi. Identifikasi lingkungan pengendapan sangat penting untuk mengetahui pola persebaran reservoir dan perubahan fasies yang terjadi dengan bantuan integrasi data sumur dan seismik. Sampai sekarang penelitian pada daerah ini belum dibuat mendetail hingga tiap sikuennya, maka pada penelitian ini akan menghasilkan peta lateral fasies batupasir hingga tiap sikuen yang teradapat pada daerah telitian.

\section{Geologi Regional}

Cekungan Jawa Barat Utara (Gambar 1) berada diantara Bogor Trough pada bagian selatan, paparan sunda bagian Utara, Tinggian Tanggerang pada bagian Barat dan Tinggian Arjawinangun pada bagian Timur yang termasuk cekungan busur belakang [7]. Cekungan Jawa Barat Utara memiliki beberapa Sub cekungan yaitu Sub cekungan Ciputat, Sub cekungan Pasir Putih, dan Sub Cekungan Jatibarang.

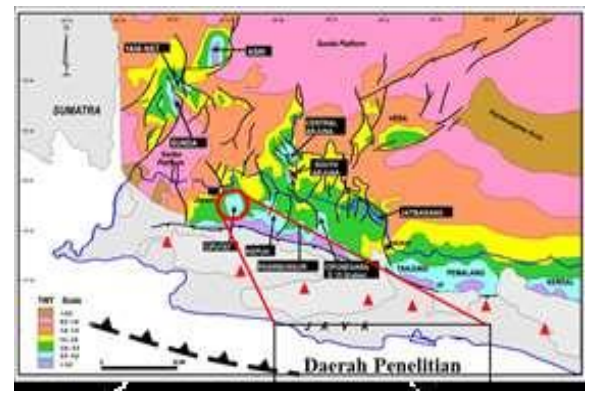

Gambar 1. Peta Tektonik Regional dan Skema Struktur Cross Section Barat - Timur [4]
Lapangan "X" berada pada Sub Cekungan Ciputat yang pada bagian barat dibatasi oleh Tinggian Tangerang dan Tinggian Rengasdengklok pada bagian Timur

\section{Stratigrafi Regional}

Urutan Formasi batuan dari yang tertua ke Formasi batuan termuda berdasarkan regional (Gambar 2) adalah Formasi Jatibarang dengan umur Eosen sampai Oligosen Tengah yang terdiri dari hasil volkanik klastik seperti tuff, andesitic dan batupasir volkanik, kemudian Formasi Talangakar dengan umur Oligosen Akhir sampai Miosen Awal yang terdiri dari batuan silisiklastik pada bagian bawah dan semakin keatas pengaruh dari volkanik semakin menurun dan lingkungan pengendapan berubah menjadi lingkungan pengendapan Laut-Deltaik, Formasi Baturaja dengan umur Miosen Awal terdiri dari karbonat bioklastik dan reefal karbonat yang terendapkan di lingkungan laut, Formasi Cibulakan dengan umur Miosen Awal sampai Miosen Tengah terdiri dari batuan sedimen yang terendapkan dilaut dangkal, Formasi Parigi dengan umur Miosen Akhir dan Formasi Cisubuh dengan umur Miosen Akhir hingga masuk ke Kuarter yang didominasi oleh batulempung karbonatan dan lapisan tipis batupasir[7]. Formasi yang dianalisis berada pada Formasi Talangakar. 


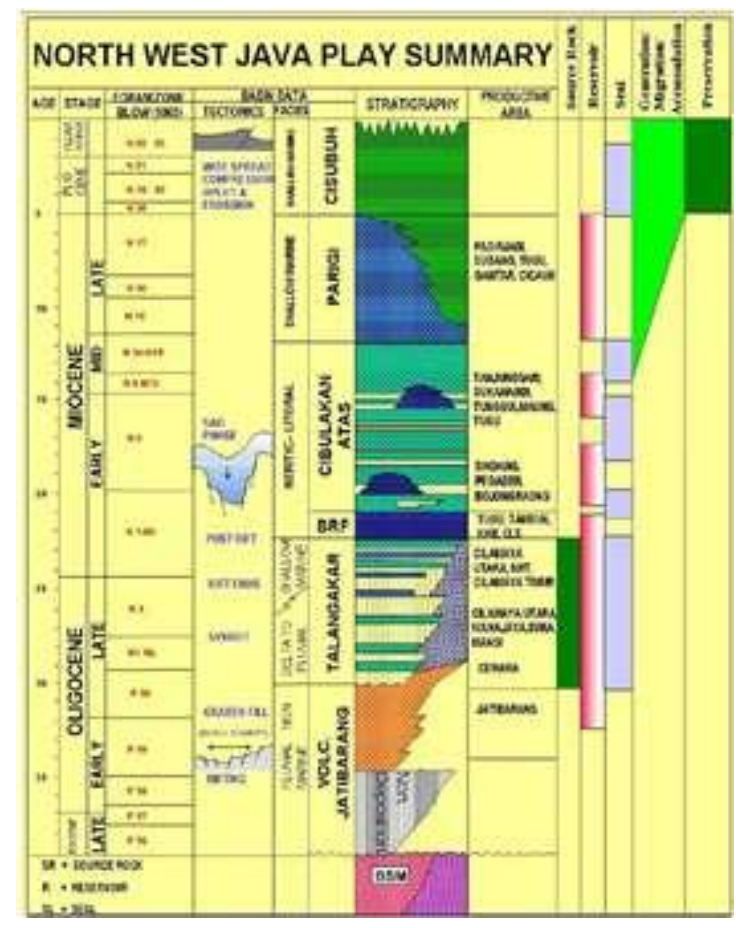

Gambar 2. Stratigrafi Cekungan Jawa Barat Utara [7]

\section{METODE PENELITIAN}

Penelitian ini menggunakan metode analisis kualitatif dengan menggunakan data berupa log sumur dan data seismik 3D didukung dengan hasil analisis biostratigrafi dan petrografi, dari data tersebut dilakukan beberapa analisis berupa analisis litologi, analisis elektrofasies, analisis sikuen stratigrafi dan analisis terhadap seismik dan atribut seismik.

Hasil dari analisis dari data-data tersebut kemudian diperoleh interpretasi dari fasies pengendapan pada setiap sikuen pada Formasi Talangakar di Lapangan " $X$ " Sub Cekungan Ciputat Cekungan Jawa Barat Utara dan kemudian menghasilkan interpretasi lingkungan pengendapannya. Akhir dari tahap penelitian adalah dilakukan pembuatan peta lingkungan pengendapan pada setiap batas sikuen yang menunjukkan distribusi penyebaran dari reservoir batupasir dengan bantuan atribut seismik RMS amplitudo, karena dengan bantuan atribut amplitudo tersebut dapat lebih mudah melakukan interpretasi fasies batupasir yaitu dengan cara melihat bagian yang kontras sedangkan jika menggunakan atribut frekuensi harus melakukan tuning pada frekuensi tertentu.

\section{HASIL DAN PEMBAHASAN}

\section{Analisis Data Sumur}

Dari tiga sumur yang terdapat pada Lapangan "X" yaitu sumur HL-01, HL-04, dan HL-05 (Gambar 3, Gambar 4, Gambar 5) akan dibahas mengenai data sumur dan interpretasinya yang terdiri dari hasil analisis biostratigrafi dan data interpretasi log sumur.

\section{Hasil Biostratigrafi Sumur HL-01}

Dari tiga sumur yang terdapat pada Lapangan "X" hanya sumur HL-01 (Tabel 1). Terdapat data biostratigrafi dan menjadi sumur kunci untuk analisis biostratigrafi. Dari hasil analisis biostratigrafi dasar dari Formasi ini berada pada 2663 MD dan lapisan teratas Formasi Talangakar berada pada $2330 \mathrm{MD}$, dimana interval Formasi Talangakar ini berumur pada kisaran Oligosen Akhir hingga Miosen Bawah yang diendapkan pada lingkungan Litoral sampai Neritik dalam.

Tabel 1 Hasil analisis biostratigrafi pada sumur $H L$ -

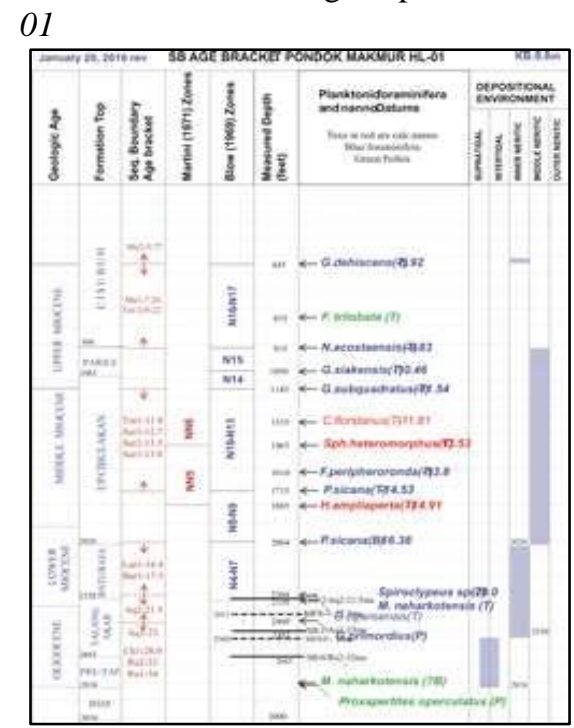




\section{Interpretasi Log Tali Kawat}

Metode awal yang digunakan untuk menentukan litologi yang membentuk suatu formasi adalah dengan menganalisis log tali kawat pada sumur HL-01, HL-04, dan HL05 (Gambar 4, Gambar 5, Gambar 6). Interpretasi litologi dengan menggunakan log tali kawat dapat ditentukan dengan menggunakan log gamma ray, log spontaneous potential, log neutron, dan log densitas. Hal pertama yang dilakukan untuk interpretasi litologi adalah membedakan litologi dengan menggunakan log gamma ray dan $\log$ spontaneous potential. Berdasarkan analisis yang sudah dikombinasikan dengan seluruh data log tali kawat, maka litologi pada lapangan "X" adalah batupasir, batubara, serpih dan batugamping klastik. Penentuan litologi batupasir menggunakan respon log tali kawat (Gambar 3), nilai gamma ray yang rendah jika dibandingkan nilai gamma ray garis dasar serpih, dan nilai log neutron yang tidak lebih dari 0,3 karena pembacaan dari log neutron akan lebih tinggi pada litologi yang mempunyai kandungan lempung [2].

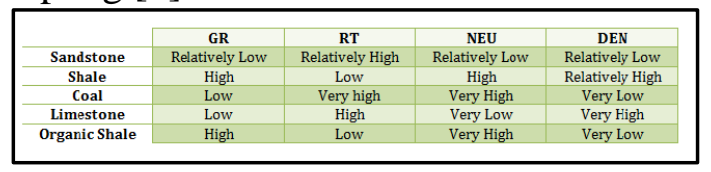

Gambar 3 Respon log tali kawat terhadap litologi [2]

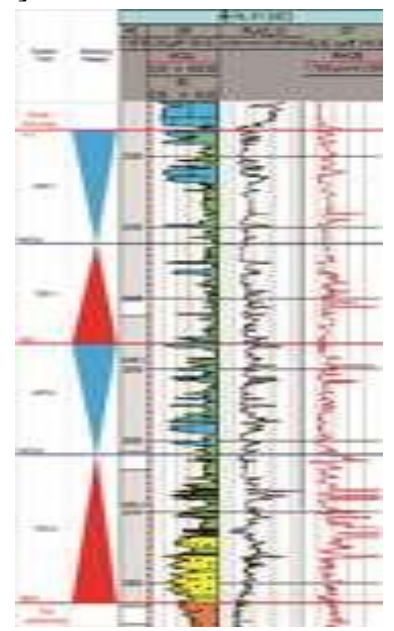

Gambar 4 Analisis Sumur HL-01

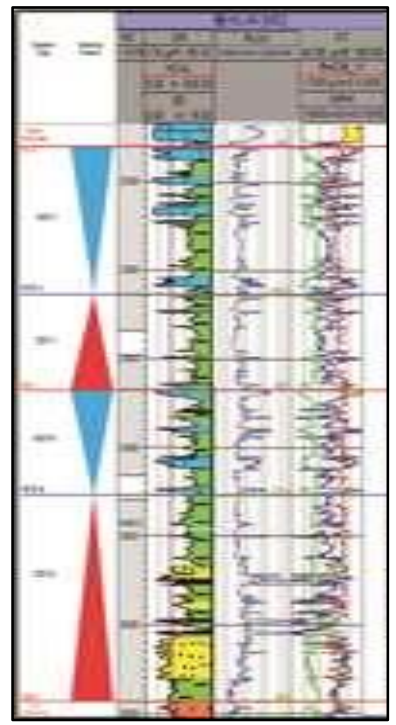

Gambar 5 Analisis Sumur HL-04

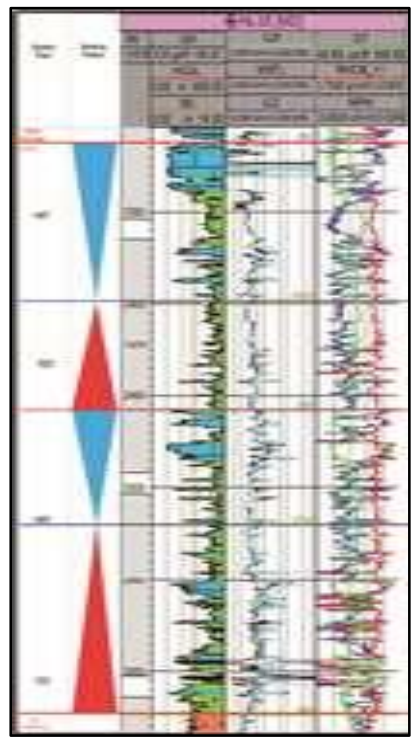

Gambar 6 Analisis Sumur HL-05

Analisis Korelasi Sikuen Stratigrafi

Sikuen stratigrafi didefinisikan sebagai studi mengenai hubungan batuan dalam kerangka kronostratigrafi terhadap lapisan (strata) yang berulang dan saling berhubungan secara genetik serta dibatasi oleh permukaan erosi atau non deposisi dan keselarasannya yang sebanding [5]. Penentuan korelasi sikuen stratigrafi (Gambar 7a) pada Lapangan " $X$ " dimulai dengan penentuan marker yang terdapat pada tiap sumur telitian. Penentuan marker 
ini dilakukan untuk menentukan maximum flooding, flooding surface, dan sequence boundary. Pada daerah telitian terdapat tiga sikuen dari lapisan terbawah ke lapisan teratas yang dapat dikorelasikan pada daerah penelitian. Tiga sikuen tersebut terdiri dari lowstand system tract, dilanjutkan dengan pengendapan transgressive system tract dan highstand system tract. Setiap sikuen dikenali dengan batas dan pola system tract dari interpretasi pola log tali kawat dan suksesi dari litologi. Hasil korelasi antar sumur tersebut dilakukan plot tiap marker pada seismik (Gambar 7b).

Pada sikuen 1 dominan berpola menghalus keatas yang terdiri dari batupasir, batulempung dan lapisan tipis batubara. Pada sikuen ini mengandung lebih banyak lapisan batupasir dibandingkan dengan sikuen yang lainnya. Pola log gamma ray yang terbentuk adalah cylindrical, serated, bell-shaped dan funnel shaped mencerminkan pola pengendapan agradasi-retro dan retro-agradasi berhubunga dengan lowstand, transgressive dan highstand system tract.
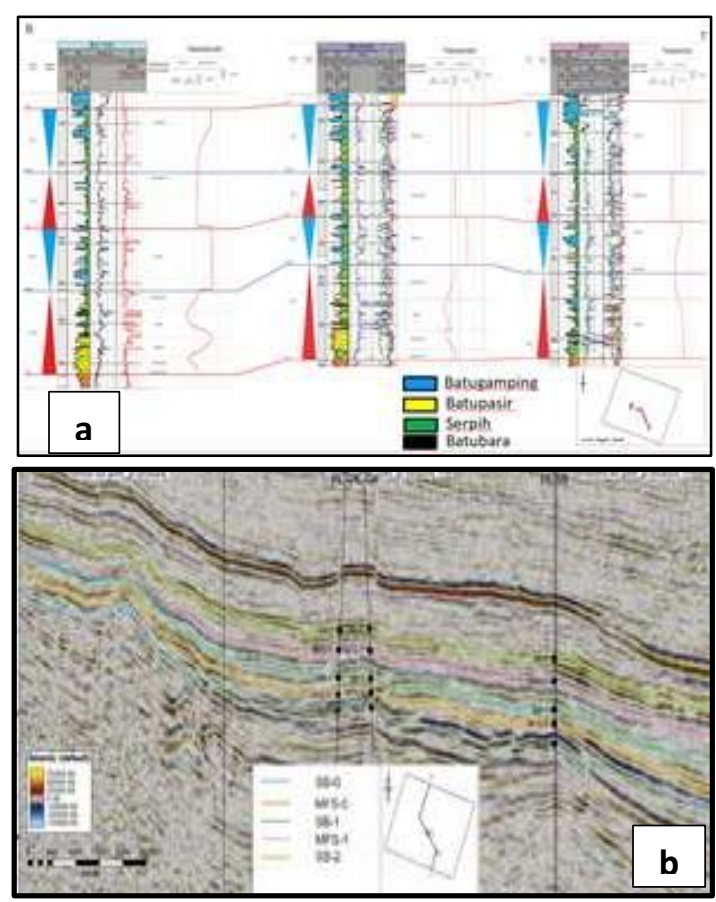

Gambar 7 Korelasi Sumur HL-01, HL-04, HL-05
Sikuen 2 terdiri dari lapisan batulempung dan batugamping dan lapisan tipis batubara. Pada sikuen ini menunjukkan adanya log yang berpola serated dan funnel yang menunjukkan adanya transgressive system tract dan highstand system tract.

\section{Analisis atribut seismik dan fasies pengendapan}

Analisis atribut seismik merupakan metode yang digunakan dalam sedimentologi seismik untuk membuat peta penyebaran fasies sedimen secara detail dalam suatu fasies pengendapan.

Sebagai suatu alat yang membantu dalam interpretasi seismik, anlisis atribut seismik memungkinkan fitur-fitur geologi lebih terlihat dan membantu geosaintis untuk melakukan analisis yang objektif.

Pada penelitian ini menggunakan salah satu atribut amplitudo yaitu amplitudo $R M S$, amplitudo RMS adalah akar dari jumlah energi dalam domain waktu yang secara matematis dapat dirumuskan sebagai berikut

$R M S=\sqrt{\frac{1}{N} \sum_{i=1}^{N} r i^{2}}$

Nilai $\mathrm{N}$ adalah jumlah amplitudo pada jangkauan (range) tertentu dan r merupakan nilai dari ampitudo. Nilai amplitude dikuadratkan dulu sebelum dirata-ratakan, maka perhitungan rms sangat sensitif terhadap nilai amplitude ekstrim [1] Hasil peta RMS amplitudo (Gambar 8 dan Gambar 10) menunjukkan warna orange ( semakin terang brightspot) mengindikasikan sedimen yang kaya akan batupasir dan bagian peta yang berwarna biru menunjukkan daerah yang kaya akan lempung atau batugamping [3] dan bagian peta yang berwarna kuning menunjukkan 
fasies transisi dimana terdapat campura batupasir dan batulempung. Secara umum, kegunaan utama atribut amplitudo adalah untuk menganalisis parameter seperti akumulasi gas dan fluida, gros litologi dan porositas, batupasir channel dan deltaic, jenis tertentu reef, ketidakselarasan, dan perubahan sikuen stratigrafi [6]. Secara umum semakin terang brightspot (semakin nyata kontras amplitudo semakin bagus prospeknya.

\section{Sikuen 1}

Saat pengendapan sikuen 1 (Gambar 7), fase pengendapan pertama dicirikan dengan sedimen batupasir yang menipis kearah timur yang ditandai dengan litologi yang berubah dominan serpih dengan sisipan batugamping pada bagian timur. Lingkungan pengendapan yang terdapat pada sikuen 1 adalah tidal channel dan tidal flat yang dimana secara umum tidal flat mengandung batupasir yang relatif rendah jadi pengendapan tidal flat sangat bagus untuk generasi batuan induk. Material sedimen diinterpretasikan berdasarkan peta isochrone yang dimana peta isochrone adalah peta ketebalan dalam domain waktu untuk menunjukkan daerah yang mengalami penipisan dan penebalan, daerah yang mengalami penipisan hingga ketebalan 0 ms diinterpretasikan sebagai tinggian purba atau paleo high begitupun sebaliknya daerah yang mengalami penebalan merupakan daerah yang diinterpretasikan sebagai depocenter (Gambar 7) berasal dari Utara Lapangan " $X$ " yaitu berupa tinggian purba yang ditransport menuju depocenter di selantan Lapangan "X".

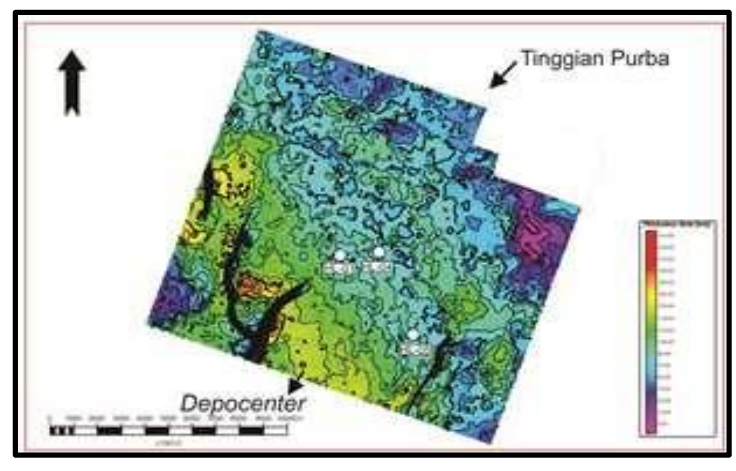

Gambar 8 Peta isochrone sikuen

Sikuen 2

Pengendapan pada sikuen 2 didominasi oleh sedimen halus yaitu batulempung dan batugamping yang berkembang seragam hampir pada ketiga sumur yang ada. Lingkunga pengendapan yang berkembang pada sikuen 2 adalah tidal channel dan tidal flat. Pengendapan berlangsung dari Utara menuju Selatan karena menurut peta isochrone (Gambar 9) diinterpretasikan daerah Utara Lapangan "X" merupakan tinggian purba (paleo high).

Disimpulkan dari peta fasies pengendapan setiap sikuen, terlihat tidak banyak berubah antara lingkunga pengendapan yang berkembang pada sikuen 1 dan sikuen 2.

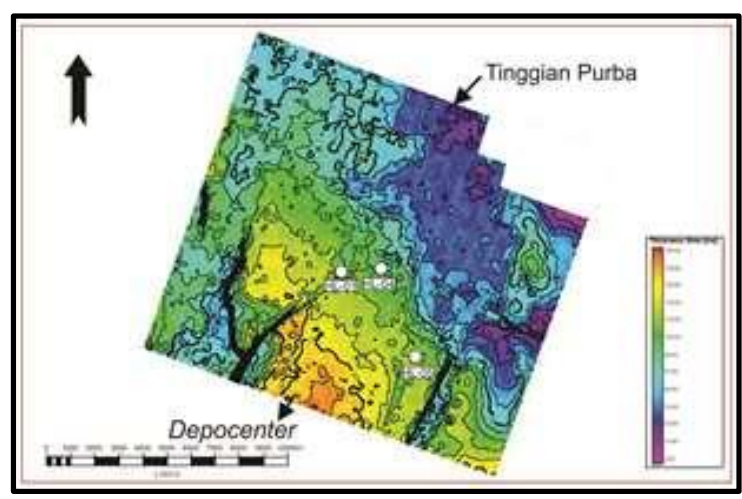

Gambar 9 Peta isochrone sikuen 2 


\section{Pola penyebaran fasies batupasir}

Pola penyebaran fasies batupasir difokuskan pada saat terbentuknya batas sikuen (SB), hal ini dikarenakan fasies batupasir secara umum terbentuk pada waktu dan horizon tertentu, horizon yang dimaksud adalah batas sikuen (SB), hal ini terjadi karena endapan yang telah tererosi akan mengalami transportasi menuju rendahan, maka dari itu untuk melihat pola persebaran fasies batupasir digunakan atribut RMS amplitudo dengan jendela 10 ms bukaan kebawah pada horizon batas sikuen (SB) (Gambar 10 dan Gambar 11).

Pola patahan yang mengontrol pada lapangan "X" relatif berarah BaratlautTenggara dan Timurlaut-Baratdaya, patahan tersebut berjenis patahan normal yang membentuk tinggian dan rendahan pada daerah penelitian sekaligus pengontrol sedimentasi pada umur tersebut.

Pola penyebaran dari lingkungan pengendapan terlihat pada sikuen 1(Gambar 12) terlihat adanya distribusi fasies batupasir yang dikontrol oleh tinggian dan rendahan terdapat pada peta isochrone memanjang dari Utara menuju Selatan yang diinterpretasikan sebagai suatu sistem channel dan litologi yang terdapat pada sekitar sumur daerah penelitian yaitu berupa batugamping yang berasal dari lingkungan tidal flat. Sedangkan pada sikuen 2 (Gambar 13) tidak jauh berbeda dengan sikuen 1, terdapat suatu amplitudo yang kontras pada peta atribut diinterpretasikan sebagai suatu fasies batupasir channel yang memanjang dari Utara menuju Selatan sedangkan amplitudo yang berwarna tidak kontras diinterpretasikan sebagai batuan batugamping atau batulempung yang menunjukkan suatu fasies tidal flat.

Kedua sikuen tersebut menunjukkan pola penyebaran yang cenderung sama yaitu terdapatnya channel yang melakukan transportasi sedimen dari paleo high yang berada di Utara daerah penelitian menuju depocenter pada bagian selatan dari daerah penelitian.

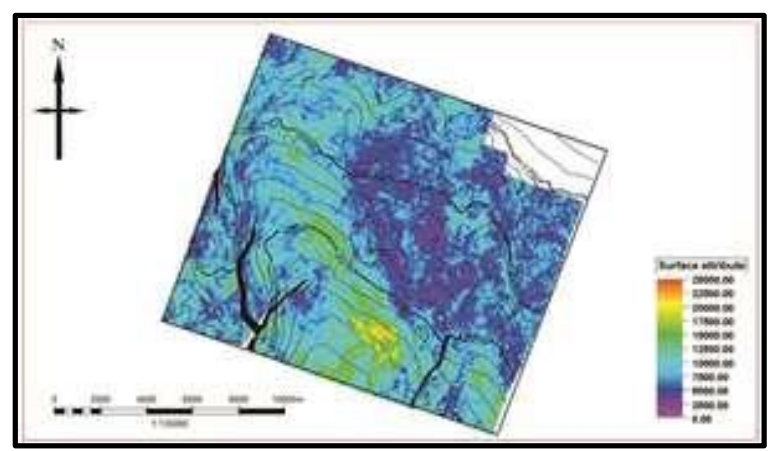

Gambar 10 Peta RMS Amplituide pada sikuen 1

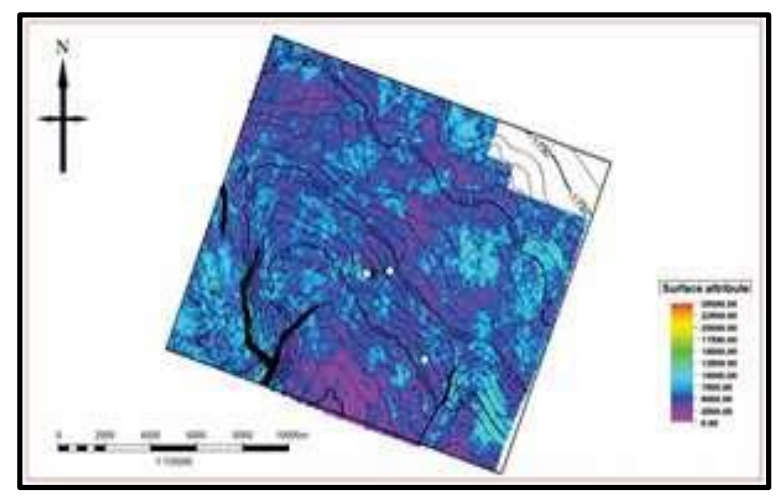

Gambar 11 Peta RMS Amplitudo pada sikuen 2

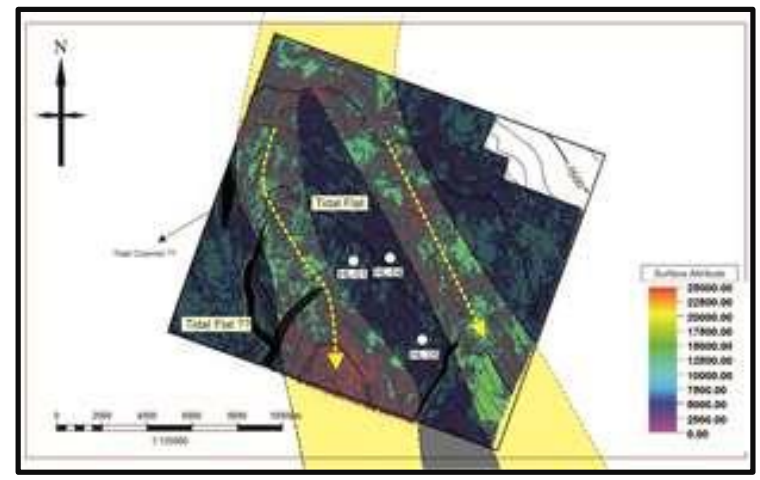

Gambar 12 Interpretasi Pola penyebaran fasies reservoir batupasir pada sikuen 1 


\section{KESIMPULAN}

1. Hasil dari analisis sesimik atribut menunjukkan karakteristik pengendapan yang berada pada sikuen 1 dan sikuen 2 tidak jauh berbeda yang dimana terdapat channel yang membentang dari Utara menuju Selatan

2. Berdasarkan peta fasies, kondisi pengendapan dipengaruhi oleh suatu sistem pasang surut air laut

3. Anomali peta atribut RMS menunjukkan adanya potensi leads yang berada pada selatan sikuen 1 terbentang dari BaratTimur

4. Analisis peta isochrone dan RMS amplitudo menujukkan bahwa sedimen dibawa dari tinggian yang berada pada Utara daerah penelitain yang dikontrol oleh tektonik dan pasang surut air laut

5. Integrasi analisis fasies atribut dan korelasi sikuen stratigrafi dapat memberikan informasi yang baik untuk interpretasi lingkungan pengendapan, fasies pengendapan, dan penyebaran lateral suatu lingkungan pengendapan yang dapat digunakan untuk penentuan letak potensi reservoir berikutnya dan analisis batuan induk.

\section{REFERENSI}

[1] Hadi, Johan Maulana., Nurwidyanto, M. Irham., Yulianto, Gatot., "Analisis Atribut Seismik Untuk Identifikasi Potensi Hidrokarbon", Jurusan Fisika FMIPA Universitas Diponegoro, Semarang, 2006.

[2] Harsono, A. Evaluasi Formasi dan Aplikasi Log. Sclumberger Oil Field, Edisi ke 8, Jakarta, 1997.

[3] Hossain, Shakhawat., "Application of seismik attribute analysis in fuvial seismik." Journal of PetroleumExploration and Production Technology, hal 1009-1019, 2019.

[4] Noble, R.A., Pratomo, K.H., Nugrahanto, K., , "Petroleum systems of Northwest Java, Indonesia", Proceedings of the Petroleum System of SE Asia and Australasia Conference, IPA Symposium, hal 585-600,1997.

[5] Posamantier, dan Allen.. "Silisiclastic Sequence Stratigraphy Concept and Aplication." Society for Sedimentary Geology, Tulsa, Oklahoma, 1999.

[6] Sukmono."Inversi Seismik untuk Karakteristik Reservoar." Lab. Teknik Geofisika, Institut Teknologi Bandung, 2000.

[7] Suyono., Sahudi, K., Prasetya, I., , "Exploration In West Java : Play Concept In The Past, Present, and Future, Efforts To Maintain Reserve Growth", Proceedings, Indonesian Petroleum Association, Thirtieth Annual Convention and Exhibition, hal $267-281,2005$ 